\title{
Composites
}

\section{Conductive hybrid polymer composites based on recycled carbon fibres and carbon nanofillers}

\author{
Marcel Zambrzycki ${ }^{1}$ (1) and Aneta Fraczek-Szczypta ${ }^{1, *}$ (1) \\ ${ }^{1}$ Faculty of Materials Science and Ceramics, AGH University of Science and Technology, Al. Mickiewicza 30, 30-059 Cracow, Poland
}

Received: 10 November 2017

Accepted: 22 January 2018

Published online:

2 February 2018

(C) The Author(s) 2018. This article is an open access publication

\begin{abstract}
The aim of this study was to investigate potential applications of milled secondary carbon fibres as a primary filler in conductive polymer composites. The examined composites were based on epoxy resin, milled secondary carbon fibres and selected carbon nanoadditive used as a secondary conductive filler. Three kinds of nanopowders were tested: multiwalled carbon nanotubes, graphene nanoplatelets and graphitized carbon black. In the first stage of the experiment, composites with different percentages of carbon fibres were examined in order to determine the electrical conductivity and percolation threshold. Subsequently, the most conductive composition (70\% of carbon fibres, $\sigma=9.05 \mathrm{~S} \mathrm{~cm}^{-1}$ ) was modified by adding nanofillers. The addition of carbon nanotubes caused more than twofold increase in in-plane conductivity to $20.18 \mathrm{~S} \mathrm{~cm}^{-1}$. The composites with graphene nanoplatelets showed deterioration of properties due to strongly increased viscosity of a binder with graphene. Small loadings of graphitized carbon black had a minor positive impact on the electrical conductivity and mechanical properties of composites.
\end{abstract}

\section{Introduction}

In recent years, conductive polymer composites (CPC) have been subjected to extensive research. Most of the studies resulted in numerous commercial applications of CPC, e.g., as bipolar plates for polymer membrane fuel cells, organic solar cells, conductive adhesives and paints, pressure and strain sensors, actuators, biomaterials, etc. [1-5]. This type of composites consists of an insulating polymer matrix and an electrically conductive filler which provides a continuous conduction network due to the percolation mechanism. The most frequently used conductive fillers are graphite, carbon fibres (CF), carbon black, metal powders, carbon nanotubes, graphene, etc. [6-8]. A well-known phenomenon is the synergic effect on the composites conductivity related to the use of more than one filler $[9,10]$. The diversity of particles sizes and shapes leads to a denser packaging of the material and thus promotes better contacts between the grains and prolonged non-interrupted conduction paths. Therefore, the most advantageous formulations usually contain both the relatively large-sized grains ensuring the non-interrupted conductivity in their volume and another finer component which improves the contact

Address correspondence to E-mail: afraczek@agh.edu.pl 
between them, filling the gaps between grains [7]. Moreover, the use of filler in a nanometric scale may reduce the tunnelling distance through the polymer which coats the coarse grains [11]. The shape of the particles is as important as their size. It has been shown that the fillers with a higher aspect ratio, such as carbon nanotubes or graphene, display much better results than the spherical particles, e.g., carbon black [10-14]. One of the most interesting fillers used in CPC are carbon fibres [10,15-17]. They are characterized by efficient mechanical properties, high aspect ratio, low density, high chemical resistance and relatively high electrical conductivity. Taking into account current green politics trends and economic factors, the research into recycled carbon fibres used as a conductive filler in CPC seems to be the matter of a particular interest [18]. However, so far, few works have been focused on investigating the electrical properties of composites based on high contents of secondary carbon fibres (sCF). Currently very intensively, apart from the development of methods of economical recycling of carbon fibres from polymer composites, they are also looking for areas of their reuse with maintaining their maximum properties. Therefore, their usage as a phase which improving electrical properties in conductive composites seems to be intentional. The biggest problem in the reuse of $\mathrm{SCF}$ is the deterioration in their mechanical properties during recycling [19]. In the case of $\mathrm{sCFs}$ used as a conductive filler, their mechanical properties are not as important as in the structural applications. Despite some weakening, $\mathrm{sCF}$ seems to offer distinctly better mechanical properties than the composites with graphite which is one of the most common conductive fillers [8]. In comparison with the virgin fibres, the $\mathrm{SCF}$ may decrease the $\mathrm{O} / \mathrm{C}$ ratio on their surface. In general, the lower concentration of functional groups and the higher content of graphitic carbons promote the high electrical conductivity of the material due to the presence of nondefected $\mathrm{sp}^{2}$ carbon bonds [1]. On the other hand, Raman studies conducted by Jiang and Pickering show the increase in both the overall carbon percentage and the disorder of the structure during the CF recycling. Such a phenomenon should lead to the decrease in fibres conductivity [20].

The aim of this study was to assess the suitability of milled PAN-derived recycled carbon fibres used as a primary filler in CPC and to investigate the effect of nanoadditives-multiwalled carbon nanotubes
(MWCNT), graphene nanoplatelets (GN) and graphitized carbon black (GCB)—on electrical, mechanical and thermal properties of the composites. Particular attention has been paid to the latter two nanoadditives, since they have been much less investigated as filler to CPC in comparison with carbon nanotubes or non-modified carbon black.

\section{Experimental}

\section{Materials}

The low molecular weight epoxy resin (EP) Epidian 601 (viscosity about 700-1100 mPa s) cross-linked with polyamine (trade name-ET) both supplied by Ciech-Sarzyna S.A. was used as a matrix of CPC. The milled polyacrylonitrile-derived secondary carbon fibres (Fig. 1a) provided by SGL Carbon Poland S.A. were used as a primary conductive filler. The multiwalled carbon nanotubes (Fig. 1b), graphene nanoplatelets (Fig. 1c) and graphitized carbon black (Fig. 1d) were used as secondary conductive fillers. MWCNT and GN were supplied by Nanostructured \& Amorphous Materials Inc., while the graphitized carbon black was provided by SGL Carbon Poland S.A. The physical characteristics of all the applied fillers are presented in Table 1.

\section{Samples preparation}

The composites preparation began with sonication of nanopowder suspensions in epoxy for $90 \mathrm{~min}$, using a tip sonicator (Palmer Instruments, model: CP $130 \mathrm{~PB})$. Even though during the process the suspensions were cooled with ice, the compositions which contained more than $2 \mathrm{wt} \%$ of MWCNT or GCB and over $0.5 \mathrm{wt} \%$ of GN revealed the poor heat dissipation and intensive heating due to a very high viscosity of suspensions. Therefore, to avoid thermal degradation of epoxy, the compositions containing more than the mentioned percentages of nanopowders were mixed mechanically. Next, the suspensions were mixed with the milled $\mathrm{sCF}$ for $15 \mathrm{~min}$. After that, the curing agent was added to the mixtures at the 8.33 EP:1.67 ET weight ratio and the mixing process was repeated. The obtained compositions were subjected to hot uniaxial pressing at $85{ }^{\circ} \mathrm{C}$ and pressure of $20 \mathrm{MPa}$ for $30 \mathrm{~min}$. The edges of the samples were sandpapered in order to remove the 

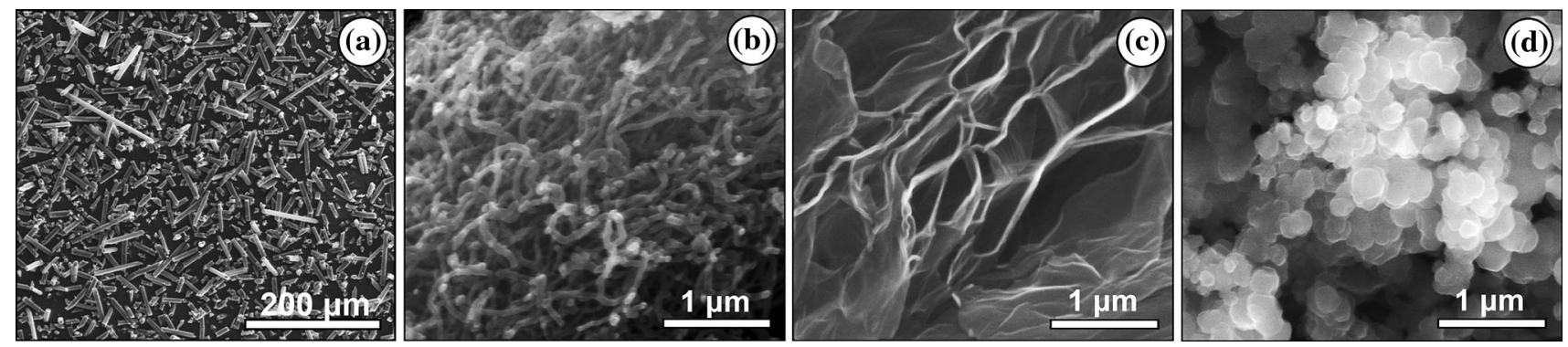

Figure 1 SEM micrographs of the applied fillers. a Milled secondary carbon fibres, $\mathbf{b}$ multiwalled carbon nanotubes, $\mathbf{c}$ graphene nanoplatelets, d DSX graphitized carbon black.

Table 1 Physical properties of used fillers

\begin{tabular}{llllll}
\hline Filler type & Diameter $(\mu \mathrm{m})$ & Length $(\mu \mathrm{m})$ & Thickness $(\mathrm{nm})$ & Specific surface $\left.\operatorname{area}_{\left(\mathrm{m}^{2}\right.} \mathrm{g}^{-1}\right)$ & Purity $(\%)$ \\
\hline Milled secondary carbon fibres & 7.28 & $50-230$ & - & 1.86 & - \\
Graphene nanoplatelets & $2-10$ & - & $1-3$ & $500-700$ & 98 \\
Multiwalled carbon nanotubes & $0.01-0.03$ & $1-2$ & - & 260 & 95 \\
Graphitized carbon black & $0.1-1.0$ & - & - & 11.4 & 99.8 \\
\hline
\end{tabular}

top layer of the composite which might contain a bigger amount of polymer than the interior material.

\section{Methods}

The microstructure of the composites and the morphology of the fillers were studied using Nova Nano SEM 200 scanning electron microscope. The energy of electron beam measured from 10 to $18 \mathrm{kV}$. The surface chemistry of $\mathrm{sCF}$ was investigated by means of X-ray photoelectron spectroscopy (XPS) (Vacuum Systems Workshop Ltd.). The radiation source was a $200 \mathrm{~W}$ X-ray tube with $\mathrm{Mg}$ anode, line $\mathrm{K} \alpha$. The depth penetration of the radiation equalled $5 \mathrm{~nm}$. The electron energy analyser was working in FAT mode with the pass energy of $22 \mathrm{eV}$. The shift of the binding energy caused by the surface charging effect was calibrated by assuming the binding energy of $\mathrm{C} 1 \mathrm{~s}$ to be $284 \mathrm{eV}$. The in-plane electrical conductivity measurement was carried out with AX-18B digital multimetre. In order to minimize disturbances of the measurement, copper plate electrodes were attached to the edges of the samples with a constant pressure applied by tightening the clamping screws. The mechanical properties of the composites were investigated by three-point bending test in Zwick 1425 universal testing machine. The load was applied with a constant feed rate of $2 \mathrm{~mm} / \mathrm{min}$. The target dimensions of the investigated samples were: $h=3 \mathrm{~mm}, a=15 \mathrm{~mm}$ and $l=80 \mathrm{~mm}$, and the support spacing measured $63 \mathrm{~mm}$. The obtained results were processed using testXpert II software provided by the manufacturer. The thermogravimetric studies were conducted using thermal analyser NETZSCH STA 449 F3 Jupiter ${ }^{\circledR}$. The measurements were performed in $\mathrm{N}_{2}$ protective atmosphere with the flow equalling $50 \mathrm{~mL} \mathrm{~min}^{-1}$ and the heating rate of $10 \mathrm{~K} \mathrm{~min}^{-1}$.

\section{Results and discussion}

\section{Secondary carbon fibres characterization}

\section{Morphology}

The morphology and the surface of secondary carbon fibres were investigated using scanning electron microscope in a magnification range $375-20000 \times$. The selected micrographs of milled $\mathrm{SCF}$ are shown in Fig. 2. The studies showed that majority of the milled fibres was about $38 \pm 23 \mu \mathrm{m}$ long. Also, a relatively low number of small particles of crushed fibres measuring approx. $5 \mu \mathrm{m}$ was observed. The highmagnification micrographs proved that, in general, the fibres had a smooth clean surface with rare and minor irregularities coming from the carbonized residues of the polymeric matrix or the polymer sizing. 
Figure 2 SEM micrographs of milled secondary carbon fibres. Magnifications: a $\times 1000, \mathbf{b} \times 5000$.
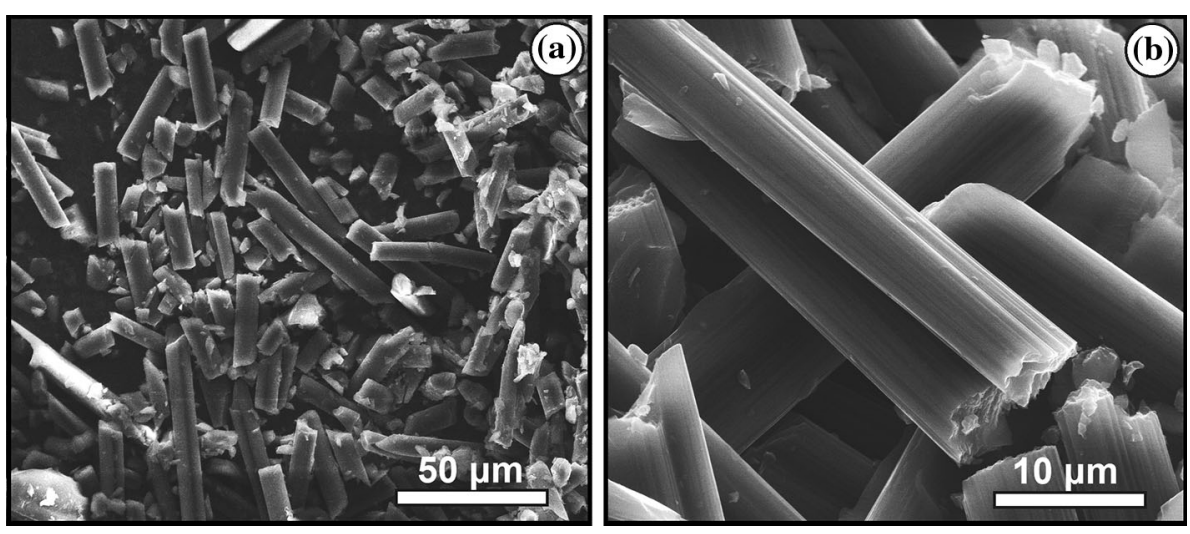

\section{Surface chemistry}

The chemical composition of the surface was examined using XPS. The testing range was up to $5 \mathrm{~nm}$ deep into the carbon fibres and the percentages of carbon (C1s), oxygen (O1s), nitrogen (N1s), sulphur (S2p) and silicone (Si2p) were also taken into account [20-23]. The results are presented in the high-resolution XPS spectra (Fig. 3) and in Tables 2 and 3. The deconvolution of $\mathrm{C} 1 \mathrm{~s}$ spectra showed that on the surface of the fibres there were mainly the carbons in $\mathrm{sp}^{2}$ hybridization $(48.18 \%)$ and the $\beta$-carbons $(25 \%)$ which stand for carbon atoms attached to carbon bonded with oxygen. The concentration of the relatively low-reactive hydroxylic groups was about $12.80 \%$. The carbonyl and carboxylic groups were present 8.78 and $5.24 \%$, respectively. The latter two groups are largely responsible for chemical reactivity of the carbon fibres. Generally, the occurrence of these functional groups is a desirable feature as it facilitates the strength of fibre-matrix interface and the chemical compatibility of $\mathrm{CF}$ and polymeric matrices. However, taking into account the discussed non-structural application of the fibres, this phenomenon does not seem to be so relevant. The O/C ratio of the investigated fibres equalled $11.01 \%$, whereas the $\mathrm{O} / \mathrm{C}$ ratio of virgin fibres was $20 \%$. This value is comparable to the results obtained by Jiang and Pickerling, where the $\mathrm{O} / \mathrm{C}$ ratio for fibres after recycling was about $15 \%$ and before it $25 \%$ [20]. The results indicate that applied recycling process decreases the concentrations of oxygen in comparison with virgin carbon fibres. The reduction in the oxygen concentration was probably caused by the $\mathrm{sCF}$ recycling process. The phenomenon of the oxygen percentage reduction on the surface of $\mathrm{sCF}$ is widely known and is usually related to the solvent or thermal recycling processes. According to the early research conducted by Zielke et al., the oxygen functionalities bonded with the surface of carbon fibres can be removed in the form of gaseous $\mathrm{CO}$ and $\mathrm{CO}_{2}$ by annealing them in high temperatures in an inert atmosphere [24]. The lower but still significant decreases in the surface oxygen concentration are induced by thermo-oxidative recycling processes. Moreover, all of the mentioned processes cause the changes in surface chemistry of SCF and the decrease in fibre's mechanical properties, particularly the reduction in tensile strength and the small decrease in elastic modulus [18-20].

\section{sCF/EP composites characterization}

The SEM images of sCF/EP composites with various filler loadings are shown in Fig. 4. The samples containing up to $70 \mathrm{wt} \%$ of sCF were characterized by good wetting of the fibres by epoxy resin and the low porosity. The porosity of composites with over $70 \%$ of filler content started to increase, and the fibres were not as well wetted as in the case of materials with a lower SCF percentage. What is important for a conductive composite, the best contact between the fibres and the highest packing density was achieved for the sample containing $70 \%$ of filler. Observations of the microstructure showed that the moulding process made some of the fibres get oriented perpendicularly to the direction of the pressing.

The in-plane electrical conductivity and apparent density of composites containing from 0 to $90 \mathrm{wt} \%$ of milled secondary carbon fibres are presented in Fig. 5a. The first recorded measurement of conductivity value was $1.1 \times 10^{-4} \mathrm{~S} \mathrm{~cm}^{-1}$ for a specimen containing $60 \mathrm{wt} \%$ of sCF. The applied apparatus did not provide readings for the samples with the smaller 

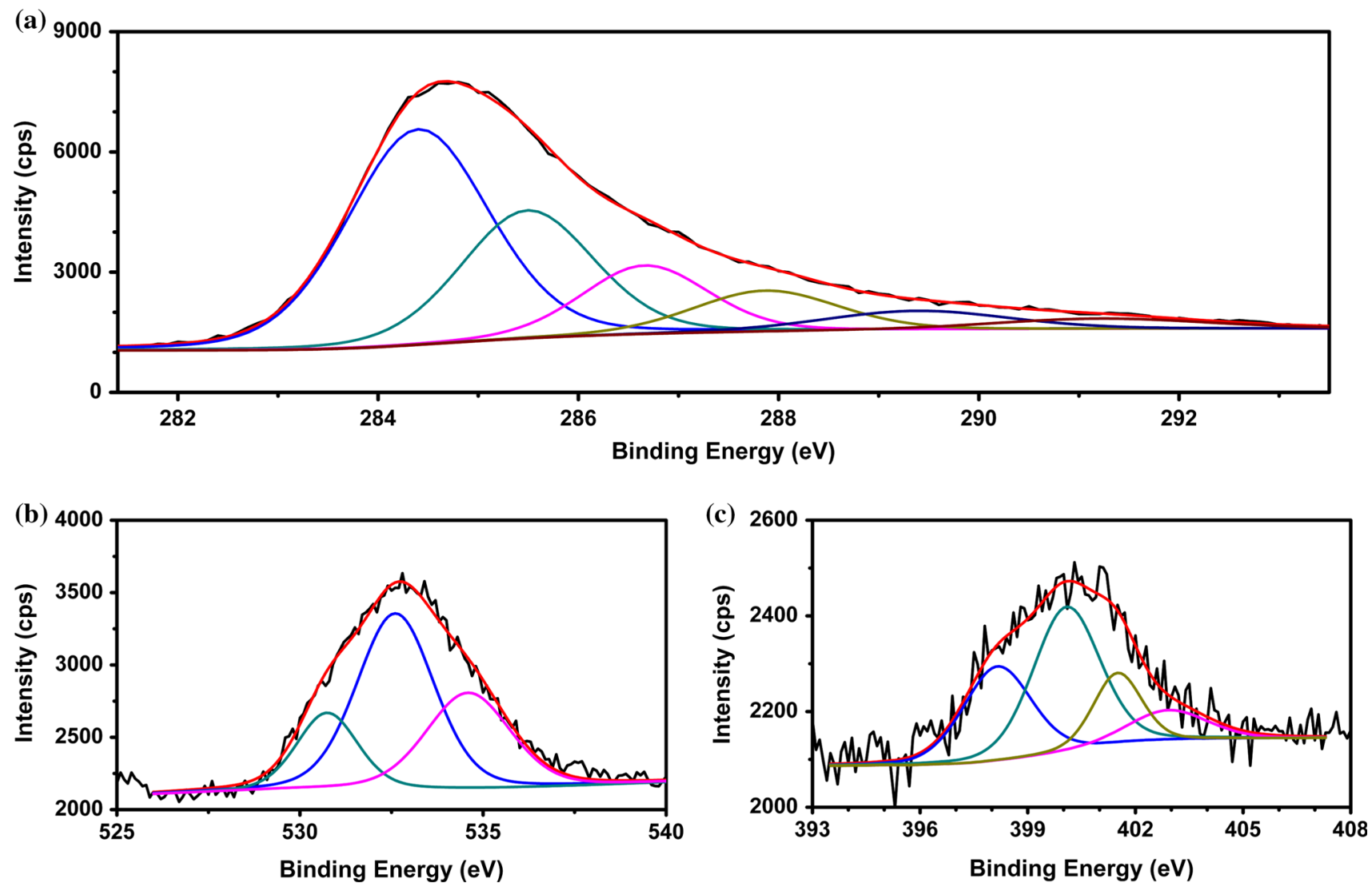

Figure 3 XPS high-resolution spectra of sCF. a Deconvoluted C1s peak, b deconvoluted O1s peak, c deconvoluted N1s peak.

Table 2 Elemental composition of the surface of secondary carbon fibres

\begin{tabular}{llllllll}
\hline Filler type & \multicolumn{7}{l}{ Atomic ratio (\%) } \\
\cline { 2 - 7 } & $\mathrm{C}$ & $\mathrm{O}$ & $\mathrm{N}$ & $\mathrm{S}$ & $\mathrm{Si}$ & $\mathrm{O} / \mathrm{C}$ \\
\hline Secondary carbon fibres & 86.23 & 9.50 & 3.86 & 0.41 & - & 11.01 \\
\hline
\end{tabular}

filler contents due to the absence of a non-interrupted conductive path and too small measuring range of the applied device. The percolation threshold-defined as a point on the conductivity curve characterized by the highest growth rate-was determined on the basis of the experimental results, fitting the Boltzmann sigmoidal function given by the following formula $[25,26]$.

$Y(x)=A_{2}+\frac{A_{1}+A_{2}}{1+\exp \left[\left(x-x_{0}\right) / \mathrm{d} x\right]}$,

where $Y(x)$ is the current conductivity value, $A_{1}$ and $A_{2}$ are minimal and maximal conductivity values, $x$ is the filler content, $x_{0}$ is the filler critical concentration (percolation threshold), and $\mathrm{d} x$ is fitting parameter dependent from the slope of an angle of function $Y(x)$ in point $x=x_{0}$. The percolation threshold

Table 3 Percentage of carbon groups on the surface of secondary carbon fibres

\begin{tabular}{|c|c|c|c|c|}
\hline Bond/group & Percentage $(\%)$ & Peak position $(\mathrm{eV})$ & Assigned binding energy $(\mathrm{eV})$ & References \\
\hline Graphitic, aromatics & 44.86 & 284.600 & $284.3-284.6$ & {$[20,22]$} \\
\hline$\pi \rightarrow \pi^{*}$ transition & 3.32 & 291.417 & 291.4-291.6 & {$[20]$} \\
\hline$\beta$-carbons & 25.00 & 285.689 & $285.1-286.0$ & {$[20,22]$} \\
\hline Hydroxylic $(\mathrm{C}-\mathrm{OH})$ & 12.80 & 286.864 & $286.1-286.7$ & {$[20,22]$} \\
\hline Carbonyls $(\mathrm{C}=\mathrm{O}, \mathrm{C}=\mathrm{N})$ & 8.78 & 288.071 & $287.1-288.1$ & {$[20,22]$} \\
\hline Carboxylic (COOH, COOC) & 5.24 & 289.579 & $289.0-289.9$ & {$[20,23]$} \\
\hline
\end{tabular}



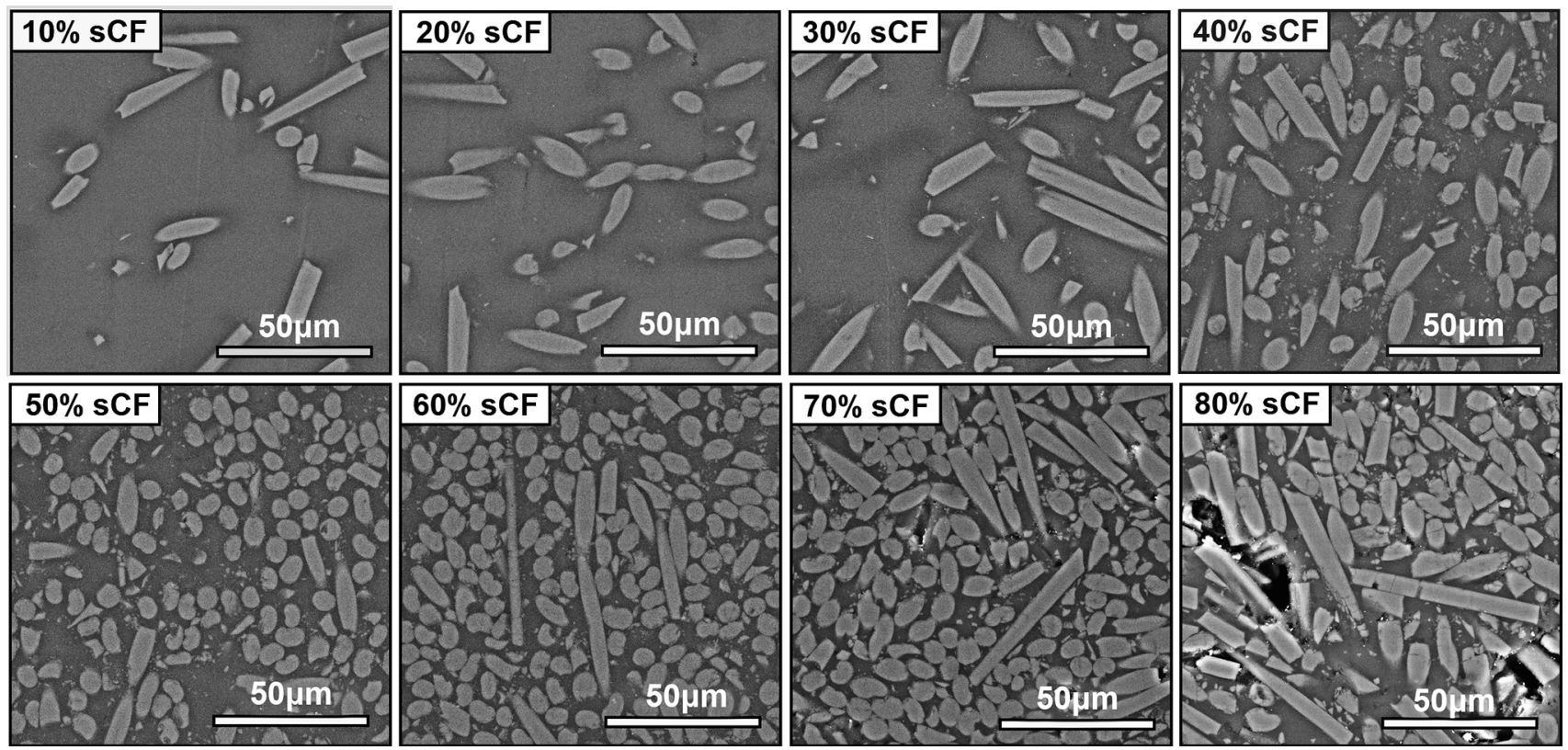

Figure 4 SEM images of sCF/EP composites containing 10-80\% of milled secondary carbon fibres.

(a)



(b)

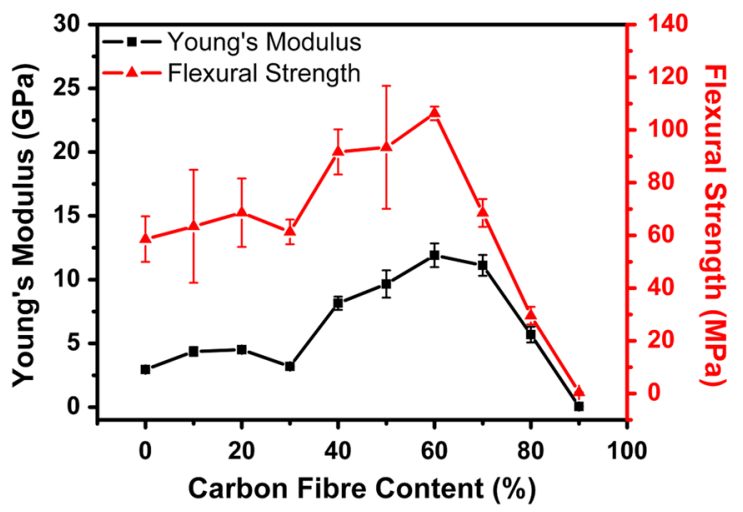

Figure 5 a In-plane electrical conductivity and apparent density of sCF/EP composites, $\mathbf{b}$ Young's modulus and flexural strength of sCF/ EP composites.

determined by this method was about $54.4 \mathrm{wt} \%$ of $\mathrm{sCF}$. Such a high value probably resulted from several factors, e.g., good wetting of the fibres by the resin, partial orientation of the fibres in one direction and high resistivity of the polymeric matrix. The calculated value of the critical concentration of the filler seems to be consistent with the microscopic observations (Fig. 4) and with the results obtained by other researchers for similar composites [10]. The highest conductivity value for the single filler composition was $9.05 \mathrm{~S} \mathrm{~cm}^{-1}$, and it was recorded for the sample containing $70 \%$ of sCF. Such a result was positively correlated with the sample high apparent density which can be treated as a determinant of extent of physical connection between single fibres in this particular case. According to the SEM micrograph observations, for the compositions with more than $70 \%$ of filler, the higher content of sCF increased the composites porosity and worsened the contact between fibres due to the insufficient amount of resin to successfully bind the filler. This phenomenon is responsible for the relatively lower values of electrical conductivity and mechanical properties of composites despite very high $\mathrm{sCF}$ contents.

The Young's modulus and flexural strength of the investigated composites are shown in Fig. 5b. As expected, addition of the milled secondary carbon fibres improved the mechanical properties of 
composites up to the point of $70 \%$ filler. The best mechanical properties were observed for the sample containing $60 \% \mathrm{sCF}$, but taking into consideration the requirements for highly conductive materials (e.g., DOI standards for bipolar plates require flexural strength $>25 \mathrm{MPa}$ and electrical conductivity $>100$ $\mathrm{S} \mathrm{cm}^{-1}$ [27]), the composition with $70 \%$ sCF was selected for further modifications with carbon nanofillers.

\section{Effect of carbon nanofillers addition on selected properties of CPC}

\section{Multiwalled carbon nanotubes}

The multiwalled carbon nanotubes of 0-6 wt\% were incorporated as a secondary filler in order to improve the electrical conductivity and mechanical properties of composites. Addition of all investigated nanopowders was related to reduction in SCF concentration so that the total fillers content $\mathrm{sCF}$ and nanoadditives) remained at $70 \mathrm{wt} \%$. The primary role of carbon nanotubes was to improve the contact between single carbon fibres [10]. An additional beneficial effect of MWCNT incorporation may be the dispersive strengthening of the matrix, which is a common phenomenon widely described in the literature $[28,29]$. The well-dispersed MWCNT filling the gaps between fibres can be observed in Fig. $6 \mathrm{~b}$.

The electrical conductivity and apparent density of hybrid composites with MWCNT are shown in Fig. 6c. The addition of MWCNT resulted in a significant increase in conductivity-up to $20.18 \mathrm{~S} \mathrm{~cm}^{-1}$ for a composition containing $4 \mathrm{wt} \%$ of nanotubes. More than twofold improvement was achieved as compared to the reference sample without nanofiller. This value exceeds the results of in-plane conductivity obtained for the analogous composites based on milled CF/EP/MWCNT which were collected by the N. A. Mohd Radzuan group [10]. The increase in composites conductivity was related mainly to the dense packaging of fillers and better contact between the fibres due to MWCNTs filling in the spaces between sCF (Fig. 6b). Such a hypothesis seems to be confirmed by the microstructure observations and high apparent density of samples. The improved density as well as the connections between the grains of conductive fillers made the electric current flow through the same cross section of composite with relatively lower losses, which resulted in the increased conductivity of composites. In case of the samples with more than $4 \mathrm{wt} \%$ of MWCNT content, the conductivity of composites began to decrease. The reason for this drop was the increase in porosity and insufficient bonding of the composite by resin due to the excessive specific surface area of the nanofillers. Therefore, the decrease in the resultant conductivity was directly caused by elongating the necessary path of the electric current and reducing the effective cross-sectional area of the porous conductor. The elongation of this pathway may be explained as the geometrical bending of the current's path around the pores which occur along this path [30]. Furthermore, comparably to the real solid, the porous materials are characterized by an effective cross-sectional area reduced by the area of pores cross section. Such a feature intensifies the electric current flow through a relatively narrower conductor and results in a correspondingly higher specific electrical resistivity of material [30]. The poor bonding and higher porosity of this sample were confirmed by its relatively lower apparent density and worse mechanical properties as compared to the sample with 4 wt $\%$ of MWCNT.

The addition of the MWCNTs had a slight positive impact on mechanical properties of the examined composites (Fig. 6d). The statistically significant improvement in flexural strength was achieved only for the samples containing $4 \%$ of nanotubes $(\sigma=85.44 \mathrm{MPa})$. In comparison with composites without MWCNTs, the observed 33\% increase in strength probably resulted from the dispersive strengthening of composite and relatively higher density of the samples. The similar data were also observed by other researchers [10]. The most crucial factors to strengthen the epoxy composites are, inter alia, the interfacial adhesion, dispersion and shape of a filler and the mechanical properties of a matrix [31]. The low viscosity of a binder and good wettability of a filler are both crucial factors to achieve good adhesion between individual phases in the case of hybrid composites with high loading of fillers. Having added nanofillers, the viscosity of a binder increases significantly, leading to a weaker binding of the material. Thus, in hybrid composites with high filler percentages, the final reinforcement is the combination of the dispersive strengthening due to the nanoparticle addition and general bonding of the material, which may be impaired by high viscosity of a binder. 
(a)

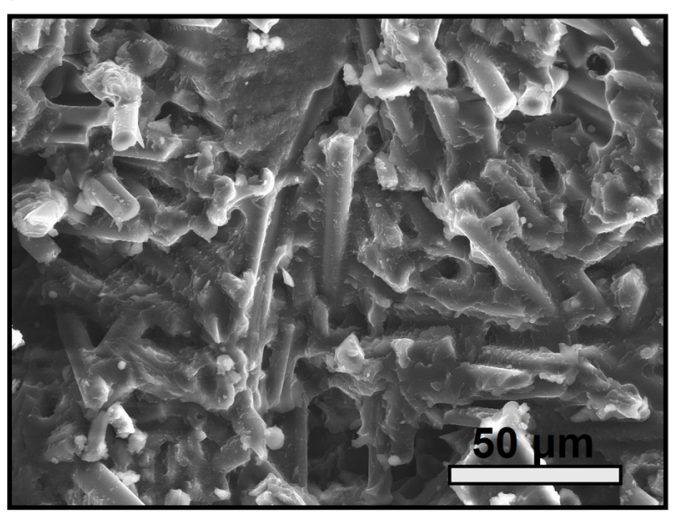

(c)



Figure 6 a Low-magnification $(\times 1000)$ and $\mathbf{b}$ high-magnification $(\times 10000)$ SEM images of sCF/EP/MWCNT4\% hybrid composite. c Effect of MWCNT addition on the in-plane electrical

\section{Graphene nanoplatelets}

The microstructure of the samples with GN is shown in Fig. $7 \mathrm{a}, \mathrm{b}$. The observations proved homogeneity of the composites, but it was difficult to identify individual graphene nanoplatelets due to the brittle fracture of the matrix. No large GN agglomerates were found, which may indicate the relatively good nanofiller dispersion. The role of graphene was similar to the other nanopowders, i.e., to improve contact between the milled sCF.

Graphene, as a material with outstanding electrical properties and the high aspect ratio, is being increasingly investigated as a conductive filler in CPC [32]. Besides the excellent conductivity, the very high specific surface area of GN (about $500 \mathrm{~m}^{2} \mathrm{~g}^{-1}$ ) should be taken into consideration in the case of investigated hybrid composites. Such a high surface area requires a significant amount of low-viscosity binder with a suitable surface energy to wet the GN (b)

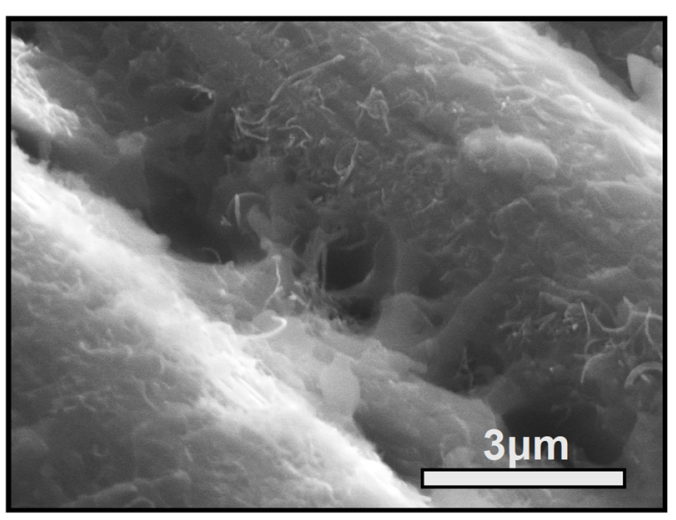

(d)

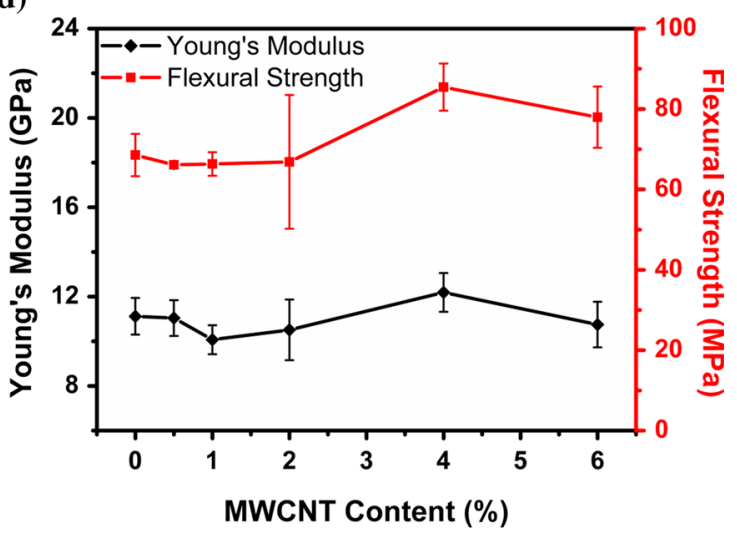

conductivity and apparent density of CPC, $\mathbf{d}$ effect of MWCNT addition on the Young's modulus and flexural strength of CPC.

successfully [33]. The conducted study showed that the $30 \mathrm{wt} \%$ of epoxy resin was insufficient to adequately wet and bind sCF/GN fillers. The density measurements revealed deterioration of the overall composite binding, namely the porosity of all the samples was increasing along with the graphene content getting bigger. After the initial conductivity increase connected with the addition of high-conductive substance, the constant decrease in conductivity was noted, despite the increasing percentage of GN (Fig. 7c). The solution to this problem may be a higher content of the binder characterized by lower viscosity. Another reason for the lack of improvement in electrical properties could be the insufficient dispersion of GN throughout the epoxy matrix.

As shown in Fig. 7d, the graphene addition also led to the slight decrease in mechanical properties, as compared to the reference sample. This behaviour probably resulted from the two competitive phenomena-dispersive matrix strengthening by GN 
(a)

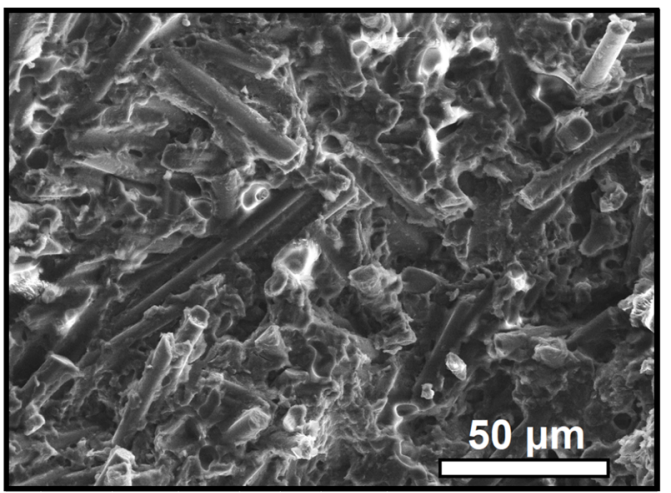

(c)



Figure 7 a Low-magnification $(\times 1000)$ and $\mathbf{b}$ high-magnification $(\times 10000)$ SEM images of sCF/EP/GN2\% hybrid composite. c Effect of GN addition on the in-plane electrical conductivity and

and deterioration of overall composite bonding due to increased viscosity of epoxy resin. Similar problems were reported by a number of other researchers [33-35]. The lowest flexural strength of the composite with $0.5 \mathrm{wt} \%$ GN can be explained by alterations in the preparation process-the nanoadditives were not sonicated for the composites containing more than 0.5 wt $\%$ of GN. The mechanical mixing of EP with graphene could result in a poorer dispersion of nanoparticles and a lower increase in viscosity of the binder; therefore, this kind of composites is endowed with better mechanical properties.

\section{Graphitized carbon black}

The SEM images of the composites with GCB are shown in Fig. 8a, b. All the investigated samples (from 0 to $40 \mathrm{wt} \%$ GCB) revealed homogenous distribution of a nanofiller; no agglomerates were observed. The analysis of micrographs of $\mathrm{sCF} / \mathrm{EP} /$ GCB with GN or MWCNT composites leads to a (b)

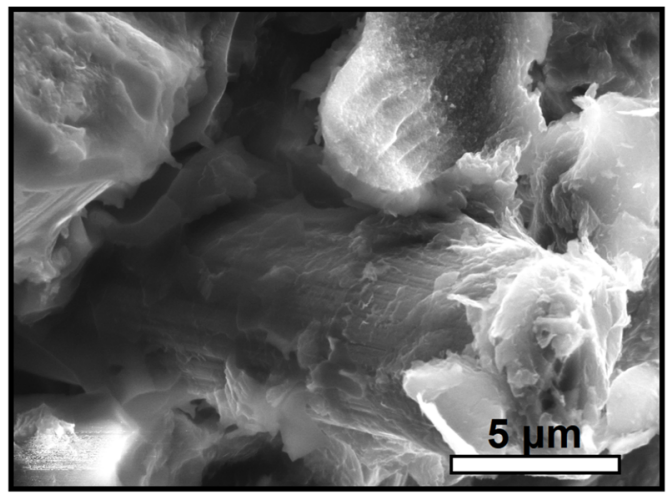

(d)

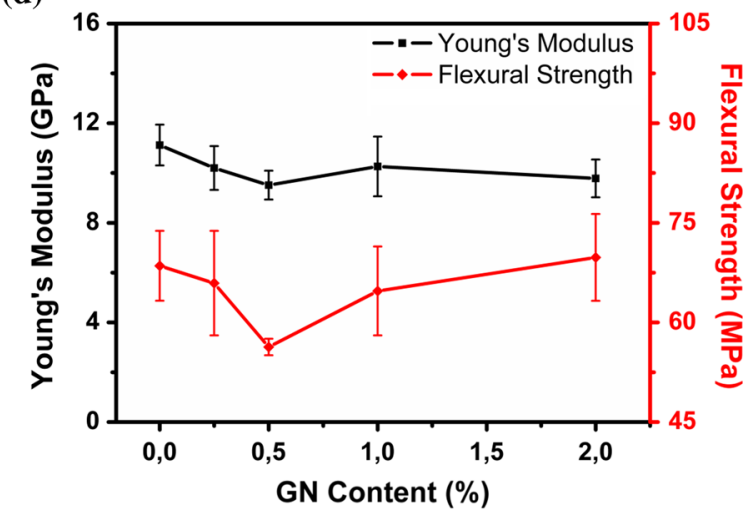

apparent density of CPC, $\mathbf{d}$ effect of GN addition on the Young's modulus and flexural strength of CPC.

conclusion that carbon black had a positive impact on wetting the carbon fibres via the binder-GCB mixture. The enhanced interface on sCF/EP-GCB boundaries resulted in relatively high apparent densities and good mechanical properties of the composites with relatively low percentages of carbon black.

Small amounts of graphitized carbon black had a positive influence on conductivity of the hybrid CPC (Fig. 8c). The initial increase in the electrical conductivity resulted mainly from the improved contact between fillers thanks to the presence of fine GCB. The highest electrical conductivity for this type of composites was observed for the sample containing $10 \%$ of GCB $\left(12.3 \mathrm{~S} \mathrm{~cm}^{-1}\right)$, whereas the addition of 20 wt $\%$ of GCB significantly decreased the composite conductivity. This drop was caused by a weaker material bonding and probably a higher porosity of the composites with high loading of GCB. The retarded increase in the apparent density with the increasing content of GCB, which is much denser $\left(\rho \sim 2.1 \mathrm{~g} \mathrm{~cm}^{-1}\right)$ than carbon fibres 
(a)

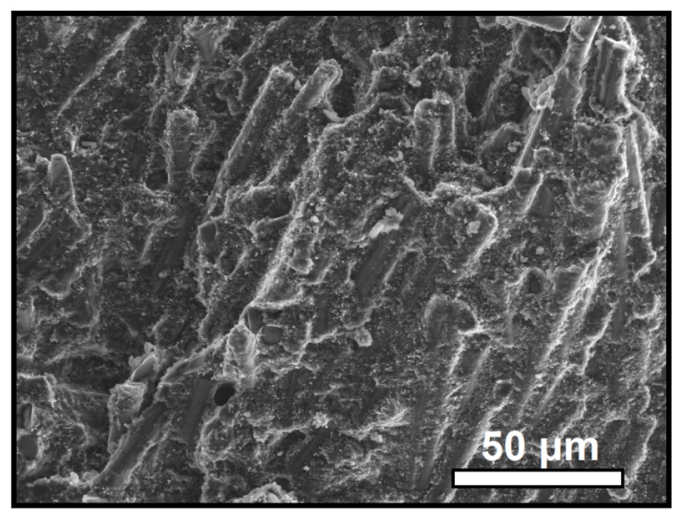

(c)

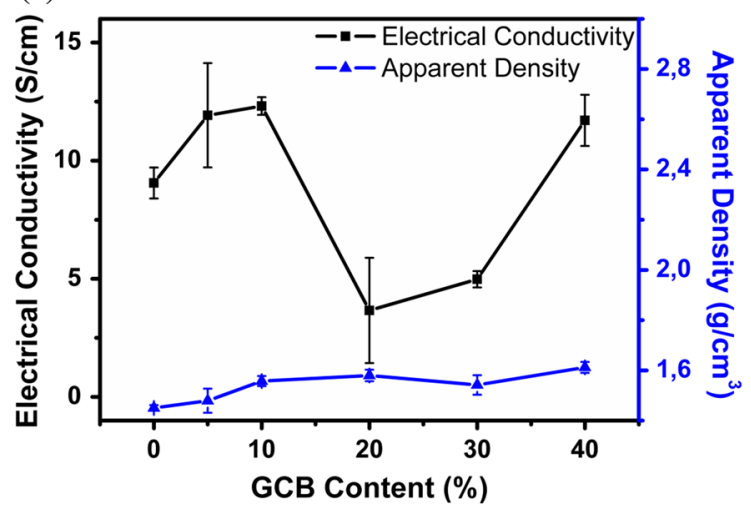

Figure 8 a Low-magnification $(\times 1000)$ and $\mathbf{b}$ high-magnification $(\times 5000)$ SEM images of $\mathrm{sCF} / \mathrm{EP} / \mathrm{GCB} 10 \%$ hybrid composite. c Effect of addition of GCB on the in-plane electrical conductivity

$\left(\rho \sim 1.8 \mathrm{~g} \mathrm{~cm}^{-1}\right)$, confirms the higher porosity and the weaker overall bonding of these composites. Despite the deterioration of the bonding of the material, higher carbon black loadings (30-40\%) induced a secondary increase in conductivity due to a large amount of highly conductive phase.

Figure $8 \mathrm{~d}$ describes how the increasing content of graphitized carbon black influences the mechanical properties of CPC. The initial increase in both the Young's modulus and flexural strength was related with dispersive strengthening and improved wettability of SCF by binder, which allowed the intensified transfer of stresses to short carbon fibres. Above the level of 10\% GCB content, the decreasing amount of carbon fibres caused deterioration of mechanical properties, especially flexural strength, despite the increasing apparent density of the composites. (b)

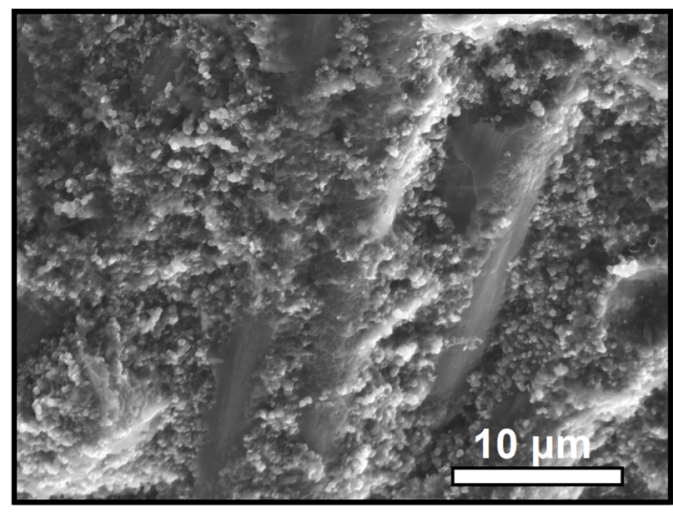

(d)

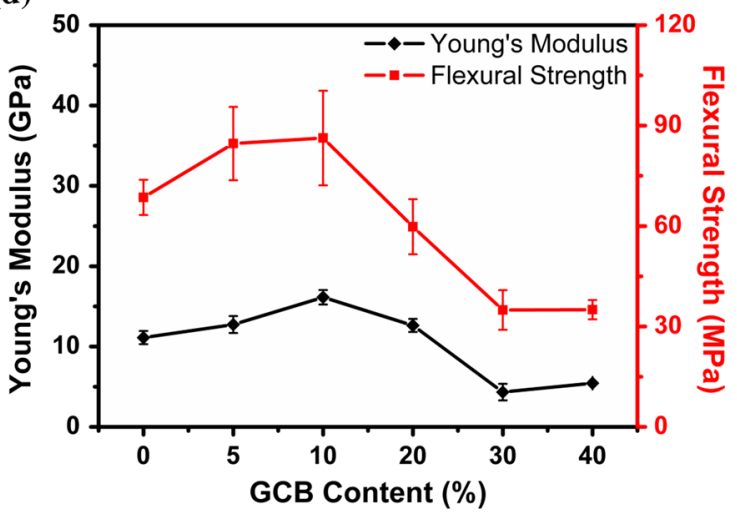

and apparent density of CPC, $\mathbf{d}$ effect of addition of GCB on the Young's modulus and flexural strength of CPC.

\section{Thermal properties of selected composites}

The thermogravimetric curves of the neat epoxy resin and selected composites are shown in Fig. 9. The influence of carbon additives in composites is observed by analysing the parameters of thermal stability on the basis of $T_{1 \%}$ ( $1 \mathrm{wt} \%$ weight loss) and $T_{5 \%}$ (5 wt $\%$ weight loss) indicators (Table 4). The presence of recycled carbon fibres in polymer increased thermal stability in comparison with pure epoxy resin-about $54{ }^{\circ} \mathrm{C}$ at $1 \%$ of weight loss and about $27{ }^{\circ} \mathrm{C}$ of $5 \mathrm{wt} \%$ of weight loss. The presence of nanoadditives in composites only in the case of MWCNT and GBC has an additional impact on thermal stability [only at $1 \mathrm{wt} \%$ of weight loss $\left(T_{1 \%}\right)$ ] in comparison with composites containing carbon fibres (EP/70\% sCF) about 26 and $29^{\circ} \mathrm{C}$, respectively. The observed growth of thermal stability and the lower temperature could be both connected with good homogenization of MWCNTs and GBCs in the composites and with a higher thermal stability of 


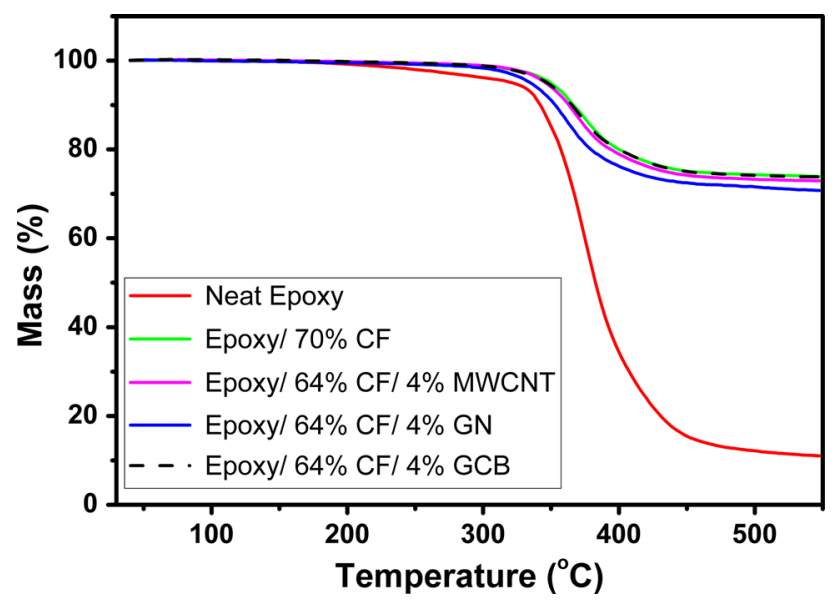

Figure 9 Thermogravimetric curves of epoxy resin and selected composites.

these two nanoadditives [36, 37]. The presence of not properly homogenized GNs in the composite (EP/ $66 \% \mathrm{sCF}+4 \% \mathrm{GN}$ ) probably has a crucial impact on thermal stability (their thermal stability at $1 \mathrm{wt} \%$ of weight loss was on the same level as for $\mathrm{EP} / 70 \% \mathrm{sCF}$ ) (Table 4$)$. The temperatures at $5 \mathrm{wt} \%$ of weight loss $\left(T_{5 \%}\right)$ for $\mathrm{EP} / 70 \% \mathrm{sCF}, \mathrm{EP} / 66 \% \mathrm{sCF}+4 \% \mathrm{GCB}$ and $\mathrm{EP} / 66 \% \mathrm{sCF}+4 \% \mathrm{MWCNT}$ are higher than for pure epoxy resin, yet the differences between the samples are not observed. Analysing the decomposition temperature of all the composites containing MWCNTs, GCBs and GNs, a slight decline of thermal stability is observed, as compared to pure epoxy resin (Table 4). The highest impact was noted for the composites containing GNs (EP/66\% sCF $+4 \% \mathrm{GN}$ ), where the onset of decomposition temperature started at about $20{ }^{\circ} \mathrm{C}$ faster than for the other composites. The increase in thermal conductivity of the composites could be the main reason which induced the accelerated decomposition of polymer [38, 39]. Carbon nanomaterials increase the heat diffusion which results in faster degradation of polymer. Another reason for the decrease in decomposition temperature for composites modified with GNs may be the poor homogenization of nanoadditives in the polymer matrix. The presence of the aggregates has a negative influence on both the mechanical and electrical properties as well as on the thermal stability. Taking into consideration the potential use of these composites (bipolar plates for polymer membrane fuel cells, organic solar cells, conductive adhesives and paints, pressure and strain sensors, actuators, biomaterials), their thermal stability is particularly important at temperatures lower than $300{ }^{\circ} \mathrm{C}$. Thus, the carbon fibre composites and, in particular, the nanotube and carbon black hybrid composites affect the increase in thermal stability and also fulfil the requirements in this regard.

\section{Conclusions}

The conducted study proved the usefulness of the milled secondary carbon fibres as a primary filler in conductive hybrid polymer composites. Thanks to the incorporation of secondary nanofillers, it was possible to modify the electrical, mechanical and thermal properties of composites. The MWCNTs turned out to be the most effective nanoadditive in terms of improving the electrical properties of hybrid systems. More than twofold increase in the electrical conductivity to $20.18 \mathrm{~S} \mathrm{~cm}^{-1}$ and slight improvement in mechanical properties $(E=12.19 \mathrm{GPa}$, $\sigma=85.44 \mathrm{MPa}$ ) were achieved for the composition with $4 \%$ of MWCNT. The addition of graphene nanoplatelets caused a slight deterioration in the overall properties of the composites. That was a result of insufficient bonding of the composite caused indirectly by the excessive specific surface area of GNs. In the case of GCB, its small amounts had a

Table 4 Results of the thermogravimetric studies

\begin{tabular}{|c|c|c|c|c|c|c|}
\hline \multirow[t]{2}{*}{ Material } & \multicolumn{2}{|c|}{ Indicators of thermal stability $\left({ }^{\circ} \mathrm{C}\right)$} & \multicolumn{3}{|c|}{ Decomposition temperature $\left({ }^{\circ} \mathrm{C}\right)$} & \multirow{2}{*}{$\begin{array}{l}\text { Residue (\%) } \\
550{ }^{\circ} \mathrm{C}\end{array}$} \\
\hline & $T_{1 \%}$ & $T_{5 \%}$ & Onset & Peak & End & \\
\hline Epoxy resin & 211 & 321 & 348 & 378 & 479 & 10.99 \\
\hline $\mathrm{EP} / 70 \% \mathrm{sCF}$ & 265 & 348 & 346 & 376 & 459 & 73.97 \\
\hline $\mathrm{EP} / 66 \% \mathrm{sCF}+4 \% \mathrm{GCB}$ & 291 & 346 & 342 & 370 & 466 & 73.82 \\
\hline $\mathrm{EP} / 66 \% \mathrm{sCF}+4 \% \mathrm{MWCNT}$ & 294 & 346 & 340 & 371 & 460 & 72.92 \\
\hline $\mathrm{EP} / 66 \% \mathrm{sCF}+4 \% \mathrm{GN}$ & 268 & 335 & 326 & 362 & 460 & 70.76 \\
\hline
\end{tabular}


positive impact on the electrical and mechanical properties of the investigated composites. The carbon black contents higher than $10 \%$ were not found to be more effective. The thermogravimetric studies showed that the presence of recycled carbon fibre in the composites and especially the addition of MWCNTs and GBCs in the hybrid composites increased the thermal stability, which was estimated on the basis of the indicator $T_{1 \%}$ about 26,39 and $38 \%$, respectively, in comparison with pure epoxy resin. These results indicated that the recycled carbon fibres could be used as fillers to CPC and the addition of a small amount of carbon nanomaterials allows the creation of hybrid composites with potential applications in electromagnetic shielding, sensors, as conductive adhesive, etc.

\section{Acknowledgements}

This work was financed from the statute funds of AGH University of Science and Technology, Faculty of Materials Science and Ceramics, Project No. 11.11.160.182.

\section{Compliance with ethical standards}

Conflict of interest The authors declare that they have no conflict of interest.

Open Access This article is distributed under the terms of the Creative Commons Attribution 4.0 International License (http://creativecommons.org/ licenses/by/4.0/), which permits unrestricted use, distribution, and reproduction in any medium, provided you give appropriate credit to the original author(s) and the source, provide a link to the Creative Commons license, and indicate if changes were made.

\section{References}

[1] Zhang W, Dehghani-Sanij AA, Blackburn RS (2007) Carbon based conductive polymer composites. J Mater Sci 42:3408-3418. https://doi.org/10.1007/s10853-007-1688-5

[2] Jin Y, Yu F, Kuppa VK (2015) Three-fold improvement in the performance of all-polymer photovoltaic devices with graphene. Mater Lett 156:161-164. https://doi.org/10.1016/j. matlet.2015.04.103
[3] Zhou Y, Zhou Y, Deng H, Fu Q (2017) A novel route towards tunable piezoresistive behavior in conductive polymer composites: addition of insulating filler with different size and surface characteristics. Compos Part A Appl Sci Manuf 96:99-109. https://doi.org/10.1016/j.compositesa. 2017.02.002

[4] Kaur G, Adhikari R, Cass P et al (2015) Electrically conductive polymers and composites for biomedical applications. RSC Adv 5:37553-37567. https://doi.org/10.1039/ C5RA01851J

[5] Keru G, Ndungu Von PG (2014) A review on carbon nanotube/polymer composites for organic solar cells. Int $\mathrm{J}$ Energy Res 38:1635-1653. https://doi.org/10.1002/er.3194

[6] Sadasivuni KK, Ponnamma D, Kim J, Thomas S (eds.) (2015) Graphene-based polymer nanocomposites in electronics. Springer International Publishing, Switzerland

[7] Antunes RA, De Oliveira MCL, Ett G, Ett V (2011) Carbon materials in composite bipolar plates for polymer electrolyte membrane fuel cells: a review of the main challenges to improve electrical performance. $J$ Power Sources 196:2945-2961. https://doi.org/10.1016/j.jpowsour.2010.12. 041

[8] Hermann A, Chaudhuri T, Spagnol P (2005) Bipolar plates for PEM fuel cells: a review. Int $\mathrm{J}$ Hydrogen Energy 30:1297-1302. https://doi.org/10.1016/j.ijhydene.2005.04. 016

[9] Mathur RB, Dhakate SR, Gupta DK et al (2008) Effect of different carbon fillers on the properties of graphite composite bipolar plate. J Mater Process Technol 203:184-192. https://doi.org/10.1016/j.jmatprotec.2007.10.044

[10] Mohd Radzuan NA, Yusuf Zakaria M, Sulong AB, Sahari J (2017) The effect of milled carbon fibre filler on electrical conductivity in highly conductive polymer composites. Compos Part B Eng 110:153-160. https://doi.org/10.1016/j. compositesb.2016.11.021

[11] Kowalczyk P, Balczunas A (2014) Wybrane zastosowania grafenu w przemyśle lotniczym i kosmicznym. Pr Inst Lotnictwa 1:160-166

[12] Bairan A, Selamat MZ, Sahadan SN et al (2016) Effect of carbon nanotubes loading in multifiller polymer composite as bipolar plate for PEM fuel cell. Procedia Chem 19:91-97. https://doi.org/10.1016/j.proche.2016.03.120

[13] Liang JZ, Yang QQ (2017) Effects of carbon fiber content and size on electric conductive properties of reinforced high density polyethylene composites. Compos Part B Eng 114:457-466. https://doi.org/10.1016/j.compositesb.2017. 02.017

[14] Yang BJ, Cho KJ, Kim GM, Lee HK (2015) Effect of CNT agglomeration on the electrical conductivity and percolation 
threshold of nanocomposites: a micromechanics-based approach. C-Comput Model Eng Sci 103:343-365

[15] Sheth C, Parekh BR, Manocha LM, Sheth P (2013) Effect of chopped carbon fiber on electrical and thermal properties of carbon reinforced epoxy composites. Int J Adv Res Electr Electron Instrum Eng 2:5551-5562

[16] Hwang IU, Yu HN, Kim SS et al (2008) Bipolar plate made of carbon fiber epoxy composite for polymer electrolyte membrane fuel cells. J Power Sources 184:90-94. https:// doi.org/10.1016/j.jpowsour.2008.05.088

[17] Vil J, Quadrat O (2002) Electrical conductivity of carbon fibres/polyester resin composites in the percolation threshold region. Eur Polym J 38:2343-2347. https://doi.org/10.1016/ S0014-3057(02)00145-3

[18] Oliveux G, Dandy LO, Leeke GA (2015) Current status of recycling of fibre reinforced polymers: review of technologies, reuse and resulting properties. Prog Mater Sci 72:61-99. https://doi.org/10.1016/j.pmatsci.2015.01.004

[19] Pimenta S, Pinho ST (2011) Recycling carbon fibre reinforced polymers for structural applications: technology review and market outlook. Waste Manag 31:378-392. https://doi.org/10.1016/j.wasman.2010.09.019

[20] Jiang G, Pickering SJ (2016) Structure-property relationship of recycled carbon fibres revealed by pyrolysis recycling process. J Mater Sci 51:1949-1958. https://doi.org/10.1007/ s10853-015-9502-2

[21] Wagner CD (1983) Sensitivity factors for XPS analysis of surface. J Electron Spectros Relat Phenomena 32:99-102

[22] Bratt A ARB XPS of carbon nanomaterials. In: Rice Univ. http://cnx.org/content/m34549/latest

[23] Zhu B, Sun S, Wang Y et al (2013) Preparation of carbon nanodots from single chain polymeric nanoparticles and theoretical investigation of the photoluminescence mechanism. J Mater Chem C 1:580-586. https://doi.org/10.1039/ C2TC00140C

[24] Zielke U, Hüttinger KJ, Hoffman WP (1996) Surface-oxidized carbon fibers: I. Surface structure and chemistry. Carbon N Y 34:983-998. https://doi.org/10.1016/00086223(96)00032-2

[25] Rahaman M, Aldalbahi A, Govindasami P et al (2017) A new insight in determining the percolation threshold of electrical conductivity for extrinsically conducting polymer composites through different sigmoidal models. Polymers (Basel) 9:1-17. https://doi.org/10.3390/polym9100527

[26] Ram R, Rahaman M, Aldalbahi A, Khastgir D (2017) Determination of percolation threshold and electrical conductivity of polyvinylidene fluoride (PVDF)/short carbon fiber (SCF) composites: effect of SCF aspect ratio. Polym Int 66:573-582. https://doi.org/10.1002/pi.5294
[27] Alo OA, Otunniyi IO, Pienaar HCvZ, Iyuke SE (2017) Materials for bipolar plates in polymer electrolyte membrane fuel cell: performance criteria and current benchmarks. Procedia Manuf 7:395-401. https://doi.org/10.1016/j. promfg.2016.12.011

[28] Wang L, Qiu J, Sakai E, Wei X (2016) The relationship between microstructure and mechanical properties of carbon nanotubes/polylactic acid nanocomposites prepared by twinscrew extrusion. Compos Part A Appl Sci Manuf 89:18-25. https://doi.org/10.1016/j.compositesa.2015.12.016

[29] Garg M, Sharma S, Mehta R (2015) Pristine and amino functionalized carbon nanotubes reinforced glass fiber epoxy composites. Compos Part A Appl Sci Manuf 76:92-101. https://doi.org/10.1016/j.compositesa.2015.05.012

[30] Montes JM, Cuevas FG, Cintas J (2008) Porosity effect on the electrical conductivity of sintered powder compacts. Appl Phys A Mater Sci Process 92:375-380. https://doi.org/ 10.1007/s00339-008-4534-y

[31] Zakaria MR, Abdul Kudus MH, Md. Akil H, Mohd Thirmizir MZ (2017) Comparative study of graphene nanoparticle and multiwall carbon nanotube filled epoxy nanocomposites based on mechanical, thermal and dielectric properties. Compos Part B Eng 119:57-66. https://doi.org/ 10.1016/j.compositesb.2017.03.023

[32] Cronin H, Silva SR, Stoeva Z et al (2017) Structural, chemical and electrical characterisation of conductive graphene-polymer composite films. Appl Surf Sci 403:403-412. https://doi.org/10.1016/j.apsusc.2017.01.132

[33] Sałacińska A (2016) Analiza Wpływu Grafenu $\mathrm{Na}$ Właściwości Kompozytów Węglowo-Epoksydowych. Trans Inst Aviat 244:83-89. https://doi.org/10.5604/05096669. 1222765

[34] Mannov E, Schmutzler H, Chandrasekaran S, Viets C, Buschhorn S, Tölle F, Schulte K (2013) Improvement of compressive strength after impact in fibre reinforced polymer composites by matrix modification with thermally reduced graphene oxide. Compos Sci Technol 87:36-41

[35] Verma D, Gope PC, Shandilya A, Gupta A (2014) Mechanical-thermal-electrical and morphological properties of graphene reinforced polymer composites: a review. Trans Indian Inst Met 67:803-816

[36] Yang H, Gong J, Wen X et al (2015) Effect of carbon black on improving thermal stability, flame retardancy and electrical conductivity of polypropylene/carbon fiber composites. Compos Sci Technol 113:31-37. https://doi.org/10.1016/j. compscitech.2015.03.013

[37] Konya Z, Vilarinho PM, Mahajan A, Kingon A (2013) Studies on the thermal decomposition of multiwall carbon nanotubes under different atmospheres. Mater Lett 90:165-168. https://doi.org/10.1016/j.matlet.2012.08.120 
[38] Ciecierska E, Boczkowska A, Kurzydlowski KJ et al (2013) The effect of carbon nanotubes on epoxy matrix nanocomposites. J Therm Anal Calorim 111:1019-1024. https://doi. org/10.1007/s10973-012-2506-0
[39] Loos MR, Coelho LAF, Pezzin SH, Amico SC (2008) Effect of carbon nanotubes addition on the mechanical and thermal properties of epoxy matrices. Mater Res 11:347-352. https:// doi.org/10.1590/S1516-14392008000300019 